\title{
A Spatiotemporal Analysis of Climatic Drivers for Observed Changes in Sahelian Vegetation Productivity (1982-2007)
}

\author{
Per Skougaard Kaspersen, Rasmus Fensholt, and Silvia Huber \\ Department of Geography and Geology, University of Copenhagen, Øster Voldgade 10, 1350 Copenhagen, Denmark \\ Correspondence should be addressed to Rasmus Fensholt, rf@geo.ku.dk
}

Received 16 February 2011; Accepted 26 September 2011

Academic Editor: Andrea Sealy

Copyright ( $) 2011$ Per Skougaard Kaspersen et al. This is an open access article distributed under the Creative Commons Attribution License, which permits unrestricted use, distribution, and reproduction in any medium, provided the original work is properly cited.

\begin{abstract}
Linear trend analysis and seasonal trend analysis are performed on gridded data of vegetation, rainfall, solar radiation flux, and air temperature, in order to examine the influence of the past three decades of climate variability and change on the Sahelian vegetation dynamics. Per-pixel correlation analyses are conducted on annual and monthly data, and analyses of change in the potential climatic constraints to the natural vegetation development from 1982-2007 are performed. The results reveal two distinct periods: (a) 1982-1994 marked by large increases in vegetation productivity and rainfall and little change in average air temperatures and solar radiation and (b) 1995-2007 characterized by no distinct trends in vegetation productivity and rainfall and increase in average air temperatures and decrease in solar radiation flux. Correlations between vegetation productivity and climatic constraints were found to be statistically significant only for rainfall explaining only a moderate degree of observed NDVI variation, indicating that nonclimatic factors are also important for the Sahelian vegetation dynamics.
\end{abstract}

\section{Introduction}

Through the second part of the 20th century the marked population growth in semiarid Africa has placed high pressure on the natural resources and increased the competition for land suitable for agriculture in this region. This led to a general intensification of existing agricultural areas, along with an expansion of agricultural activities into former marginal areas [1]. As a consequence, overall soil fertility and yield potentials have declined rapidly for many areas, resulting in additional land being brought under the plough [2]. The agricultural production of many semiarid areas of sub-Saharan Africa is characterized by a low adaptive capacity, and therefore the region is extremely vulnerable to the influence of large-scale external pressures, including that of climate change and increased climatic variability [3]. Particularly pronounced periods of droughts in the Sahel during the 1970-1980's displayed this vulnerability. These droughts had a devastating impact on the local economy and regional food security and were a key factor for the establishment of the United Nations Convention to Combat Desertification and Drought (UNCCD), giving further attention to the sensitivity of the Sahelian ecosystems and the people who depend on them [4].

The Sahel provides some of the most dramatic examples with regard to climate variability during the 20th century [5, 6]. Average rainfall amounts during 1961-1989 were $40 \%$ lower as compared to the earlier reference period (1931-1960) and display the large intrinsic interannual variability in rainfall and hence the difficulty in predicting the characteristics of future rainfall $[6,7]$. Climate change scenarios [8] and global change scenarios [9] underline that more regions in semitropical areas including the Sahel are expected to be prone to future extremes in climate variability, with persistent drought as a major problem and thus negatively impacting the natural resource base.

The "functional convergence hypothesis" suggests that ecological processes tend to adjust plant characteristics in response to ambient conditions in a way that tends to maximize growth. In essence, the functional convergence hypothesis states that resource shortages of any sort will lead to adjustments of light capture; hence light capture serves as an integrator of resource status and biochemical capacity for $\mathrm{CO}_{2}$ assimilation [10]. Variations in air temperature 


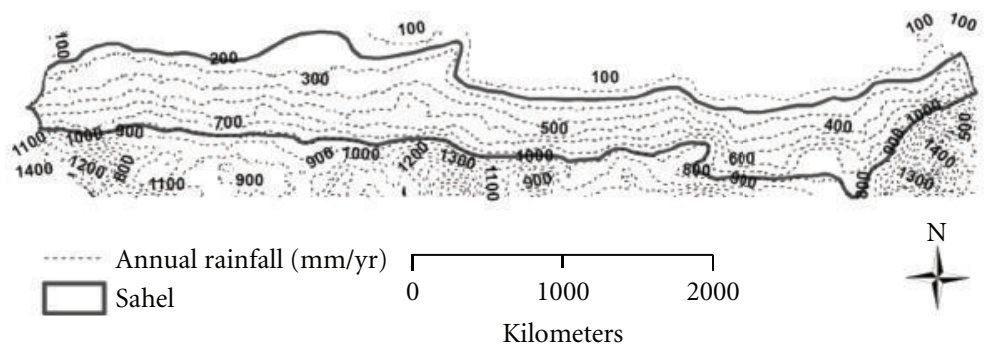

(a)

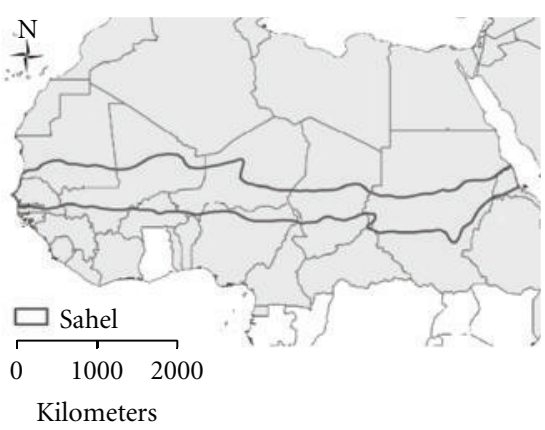

(b)

Figure 1: Delineation of the Sahel based upon the 150 and $700 \mathrm{~mm}$ rainfall isohyets. Based on the National Weather Service Climate Prediction Center, African Rainfall Estimates (RFE) annual mean rainfall 1996-2007.

and surface downward solar radiation flux are generally not expected to explain as much of the observed NDVI variance as rainfall since water availability is the most important potential climatic constraint on vegetation productivity in Sahel [11-15]. However, changes in NDVI over time could potentially be caused not only by water availability but also from other climatic constraints (solar radiation flux and air temperature) as water becomes less limiting for plant growth.

The aim of this paper is to examine the impact of the past three decades of climate variability and change in the Sahel (1982-2007) on vegetation productivity. This is accomplished through spatiotemporal analysis of earth observation- (EO-) based as well as modeled biophysical variables from reanalysis data. Analysis of vegetation trends (NDVI) combined with analysis of trends of the potential climatic constraints (water, radiation, and temperature) [16] for vegetation growth is studied to explore possible causes of the observed changes in vegetation dynamics. Theil-Sen median slope linear trend analysis (TS-LTA) is performed on annual and monthly data covering the period of 19822007 in order to examine the magnitude and direction of the long-term trends. Additionally seasonal trend analysis (STA) is conducted and combined with the output of the LTA as this enables an investigation of the importance of the observed long-term trends. Complementary, significance tests are computed in order to express the probability that the observed trends could have occurred by chance. Regression analysis between NDVI and the selected climatic variables (rainfall, incoming radiation, and air temperature) is performed in order to quantify the explanatory strength of these climatic constraints on the observed trends in annual and monthly estimates of vegetation productivity.

\section{Study Area}

The Sahel stretches from the Atlantic Ocean in the west to the Red Sea in the east (Figure 1) and is located between the southern edge of the Sahara and the northern parts of the tropical equatorial Africa, hence forming a transition zone between the arid northern and the humid southern ecoregions. Annual amounts of rainfall and vegetation cover are among the most common delineators of the Sahel $[2,15,17]$.
In the current study the Sahel is demarcated according to the average annual rainfall for the period 1996-2007 and covers the area between the 150-700 $\mathrm{mm}$ isohyets (Figure 1).

The northern parts of the Sahel are primarily dominated by open and sparse grasslands, shrublands, and sandy deserts, while cropland, open woody vegetation, and deciduous shrubland characterize the southern landscapes $[18,19]$. The region is dominated by $\mathrm{C} 4$ type plants, accounting for roughly $80 \%$ of the herbaceous layer on average, as these plants are more efficient producers at high temperatures and radiation levels, as compared to C3 plants [20].

The dynamics and movement of the intertropical convergence zone (ITCZ) is the primary driving force controlling the amount, timing, and distribution of the Sahelian rainfall [21]. Large scale convergence, carrying moisture to great heights, is associated with the location of the ITCZ and forms the basis for the seasonal rainfall regime [21, 22]. The west african monsoon (WAM) dynamics is a response to the temperature, pressure, and humidity difference between the North African continent and the tropical Atlantic [23]. The Sahelian rainy season is directly linked to the WAM, with a length of 3-6 months and an annual peak in rainfall intensity in August. The length of the rainy season decreases with increasing latitude and lasts approximately 3 months in the north and 6 months in the south [23]. Temperatures are high throughout the entire year with average values between $32-35^{\circ} \mathrm{C}$ and $20-25^{\circ} \mathrm{C}$ in the warmest and coldest month, respectively [18]. Similar to rainfall, average temperatures increase with decreasing latitude and vice versa. Temperatures are considerably lower near the coast and during the short and intense rainy season due to the effect of the increased availability of water on the components controlling the overall energy balance during this time of year $[18,24]$.

\section{Data}

Long-term datasets of biophysical variables for the Sahel are primarily based on ground-based measurements from weather stations, satellite data, or a combination of both. Weather stations are often concentrated in populated areas and in the wealthier regions leaving large areas with a very 
limited coverage in sub-Saharan Africa and the Sahel [25]. Satellite data from the AVHHR (advanced very high resolution radiometer) sensors onboard the NOAA satellite provides continuous spatiotemporal information on vegetation productivity. GIMMS (global inventory modelling and mapping studies) and NDVI (normalized difference vegetation index) based on AVHRR data are currently available from July 1981 to 2007 and are amongst the most widely used global coverage AVHRR data set. The period including full-year coverage of GIMMS data (1982-2007) thus determines the temporal extent of analyses performed.

3.1. AVHRR GIMMS NDVI. The input data used for the GIMMS data set is the global area coverage (GAC) $1 \mathrm{~B}$ product. Each GAC pixel is binned into one of the $8 \mathrm{~km}$ pixels of the output product based on a forward, nearest neighbor mapping where the GAC pixel with the highest NDVI value is selected [26]. The channels 1 and 2 data used for the GIMMS data are calibrated [27], and the derived NDVI is further adjusted using the technique of Los [28]. No atmospheric correction is applied to the GIMMS data except for volcanic stratospheric aerosol periods (1982-1984 and 1991-1994) [23]. A satellite orbital drift correction is performed using an empirical mode decomposition (EMD) transformation method of Pinzon et al. [29] removing common trends between time series of solar zenith angle (SZA) and NDVI.

3.2. Rainfall Data. The rainfall data which was selected for the current study is the Climate Prediction Center Merged Analysis of Precipitation (CMAP). The CMAP dataset consists of global monthly rainfall estimates constructed on a $2.5^{\circ}$ latitude-longitude grid for the period 1979-present. The monthly rainfall estimates are based on a combination of gauge station measurements and a variety of different satellite observations. This is done in order to ensure the optimum temporal coverage and spatial resolution and to improve the overall quality of the dataset. The satellite estimates include information on cloud properties derived from the visible (VIS) and infrared (IR) channels, outgoing longwave radiation (OLR), microwave sounding unit (MSU), and microwave scattering and emission data from the SSM/I [30]. The satellite estimates are combined with a gridded gaugebased dataset, constructed from over 6700 gauge stations globally, in order to produce the final monthly precipitation product. However, the number of rain gauge stations used for calibration varies considerably in space with an average of 11 stations for the $2.5^{\circ}$ pixels covering the Sahelian zone. The absolute values given are generally less worthy of confidence than the variability and global averages appear to be accurate to within $5-10 \%[30]$.

\subsection{Temperature Data. The NOAA NCEP CPC GHCN/} CAMS gridded air temperature dataset is a station observation-based global land monthly mean surface air temperature dataset at $0.5 \times 0.5$ latitude-longitude resolution for the period from 1948 to the present and was developed at the Climate Prediction Center, National Centers for Environmental Prediction [25]. This dataset uses a combination of two individual datasets of station observations (the Global Historical Climatology Network version 2 and the Climate Anomaly Monitoring System (GHCN + CAMS)) including the anomaly interpolation approach with spatiallytemporally varying temperature lapse rates derived from the observation-based reanalysis for topographic adjustment.

3.4. Surface Downward Solar Radiation Flux. The NOAA NCEP-DOE reanalysis-2 monthly surface downward solar radiation flux data used in the current study is based on the widely used NCEP/NCAR (National Center for Environmental Prediction and National Center for Atmospheric Research reanalysis) reanalysis. Reanalysis-2 is based on state-of-theart analysis/forecast system to perform data assimilation and is aiming at improving upon the NCEP/NCAR reanalysis by updating the parameterizations of the physical processes [31]. Gridded surface downward solar radiation flux data are provided in units of $\mathrm{W} / \mathrm{m}^{2}$ in a 1.875 -degree spatial resolution from 1979-present

\section{Methods}

Linear trend analysis (LTA) and seasonal trend analysis (STA) were performed in order to examine the past three decades of inter- and intra-annual changes in biophysical variables, such as vegetation production, rainfall, air temperature, and solar radiation flux. The linear approach is widely used $[11,32,33]$ due to its simplicity and since slope values reported on a pixel level can easily be compared since relating to the same model.

4.1. Trend Analysis. The AVHRR GIMMS 15 day NDVI composite data were aggregated to monthly observations using a maximum value composite approach to further reduce noise and to match the temporal resolution of the rainfall, air temperature, and solar radiation flux dataset. Analyses were performed on anomalies to remove the seasonal influence on the analysis outcome. The long-term trend analyses performed are based on the Theil-Sen median slope linear trend analysis (TS-LTA) known to be resistant to the impact of outliers (noise). Nonparametric tests such as Theil-Sen (TS) are considered to be robust against seasonality, nonnormality, heteroscedasticity, and temporal autocorrelation (at both intra- and interannual scale) [3439]. For this reason TS-LTA is highly applicable for studies of vegetation trends as based on timeseries of NDVI data [40]. The procedure is applied independently at each pixel and calculates the median of the slopes between all $n(n-1) / 2$ pairwise combinations of pixels over time. This approach is related to the approach of using linear least square regression trend techniques. However, the Theil-Sen median slope trend analysis (based on nonparametric statistics) is particularly effective for the estimation of trend from small and noisy samples.

4.2. Seasonal Trend Analysis. The Seasonal Trend Analysis (STA), as applied here, includes a two-stage timeseries analysis: (1) harmonic regression and (2) a nonparametric 


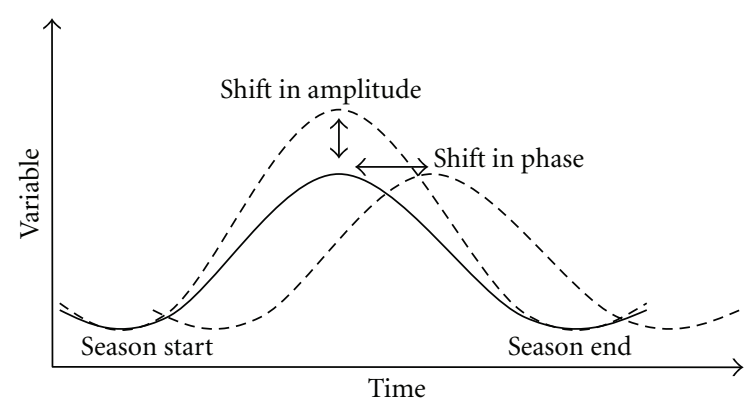

FIGURE 2: Illustration of amplitude and phase shifts as derived from the seasonal trend analysis (STA).

linear trend procedure [41]. Per-pixel harmonic regression was applied to each year of images of the timeseries of NDVI, rainfall, air temperature and solar radiation flux, respectively, to extract the mean annual image, the annual cycle, and the semiannual cycle (described by five harmonic shape parameters) which is similar to the use of Fourier analysis as applied by Hill et al. [42]. The use of two harmonics provides a generalization of the seasonal curve that balances the need to describe the basic structure of environmental response to solar input with the need to avoid influence from noise [43]. The per-pixel trends in the harmonic shape parameter images were analyzed using a Theil-Sen median slope operator by calculating the slope for each pairwise combination of samples in time. The calculated trends of median slope and intercept values on each of the five shape parameters were then calculated as seasonal curves for the beginning and the end of the series based on median values over the first and last seven years of the timeseries. Seven years were considered a suitable length to base the observed curves, as it reduces the influence of a few extreme years still covering only approximately $25 \%$ of the entire analysis period. The two shape parameters of interest in the current analysis were the amplitude 1 and the phase 1 index series. The amplitude 1 expresses any change in the magnitude of difference between annual high/low values, that is, the amplitude of the seasonal curve (Figure 2). A positive trend in the amplitude 1 index series indicates an increase in the difference between annual high/low values and vice versa. The phase 1 index series displays the interannual changes in the timing of the annual peak (Figure 2). A positive trend is a shift of the annual peak towards an earlier date and inversely for a negative trend.

4.3. Linear Correlation and Regression Analysis. Regression analyses were performed to identify the most important variables in controlling vegetation growth in the Sahel. By calculating pixel-wise Pearson product moment correlation coefficients $(r)$, the strength of linear association between NDVI and the environmental and climatic factors controlling vegetation growth (rainfall, air temperature, and solar radiation flux) was determined for the three 26-year timeseries (5\% and 10\% significance levels are used here). Linear regression analysis was conducted for both annual and monthly (June-October) data and carried out for the period
1982-2007. In order to identify the optimum lag time in vegetation response to the climatic constraint, a $0-2$-month delayed response time was tested. The monthly regression analysis was based on the months covering the average Sahelian growing season (June-October) to minimize the effect of noise in the dry season data $[17,41]$.

4.4. Testing for Significance. Statistical significance was tested using a Mann-Kendall significance test producing $z$ scores which provide information on both the significance and direction of the trend simultaneously. The Mann-Kendall significance test is measuring the significance ( $z$-scores) of a monotonic trend (a nonlinear trend indicator) but is commonly used as a trend test for the Theil-Sen median slope operator. A positive slope $(z \geq 1.96)$ represents a significant increase $(\alpha=0.05)$. Likewise, a negative slope $(z \leq-1.96)$ indicates a significant decrease $(\alpha=0.05)$ over time.

\section{Results and Discussion}

5.1. Linear Trend Analysis. The results of the per-pixel linear trend analyses of NDVI, rainfall, air temperature, and surface solar radiation flux for the entire period of available NDVI data (1982-2007) are shown in Figure 3. Only the slope values for pixels with significant trends at the $10 \%$ confidence level are reported. As evident from Figure 3(a) positive NDVI slope values are present throughout the entire region with only a few minor exceptions (average annual NDVI slope of Sahel = 0.025). As expected, slopes are found to be higher with decreasing latitude and vice versa. The Sahel natural biomass production tends to increase with decreasing latitude causing the difference in increment between the northern and southern parts. It is noticeable that the areas with significant trends (10\% level) correspondingly tend to be concentrated at lower latitudes. This finding agrees with the results obtained by several other studies based on analysis covering a period until 1999, 2003, and 2007 $[11,17,44-47]$. Performing trend analysis on NDVI for the most northern areas of the Sahel, characterized by very limited vegetation growth, may not be appropriate due to the increased influence of soil background and sensor effects on the NDVI signal [48]. This is most likely the cause for the larger fraction of pixels with insignificant trends in the higher latitudes. The observed positive NDVI trend for the Sahel in general is not unexpected as the period of observations begins at the time of some of the most severe droughts ever recorded in the region. As no clear NDVI trend is evident after the mid 90's the observed increase is most likely an indication of vegetation recovery following the droughts of the early 80's and not a sign of continuous increment of biomass production. An increase in annual rainfall can be observed over most of the Sahel as positive slopes dominate the region (Figure 3(b)). Approximately $50 \%$ of the observed positive trends are significant at the $10 \%$ confidence level. Slope values range between $4-7 \mathrm{~mm} / \mathrm{yr}$, which corresponds to an average slope value of $3 \mathrm{~mm} / \mathrm{yr}$ for the Sahel as a whole. This amounts to a total rainfall increase of $80 \mathrm{~mm}$ on average over the period of 1982-2007. It is noticeable that 


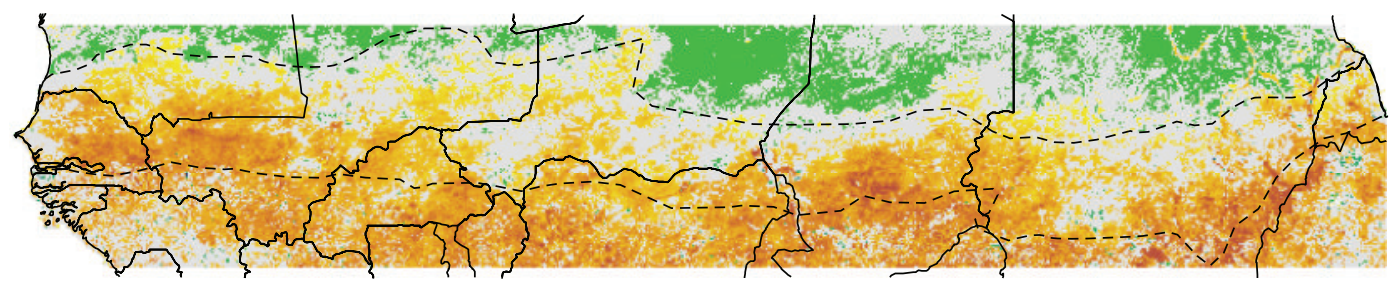

(a)

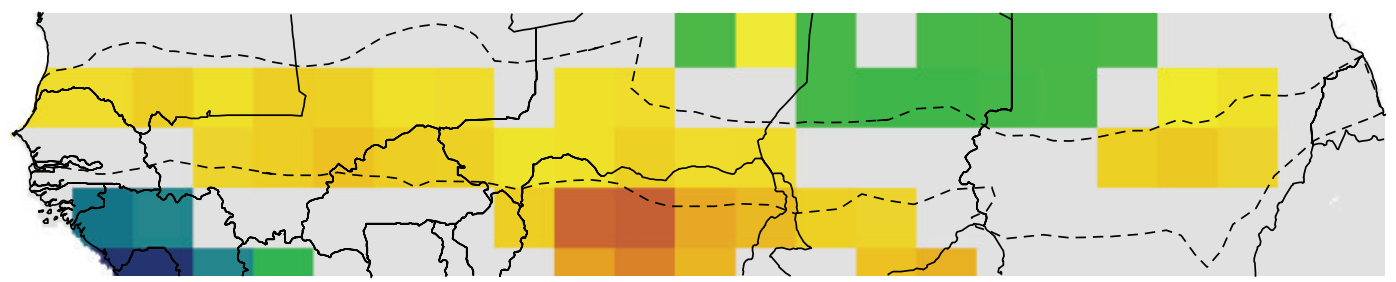

(b)

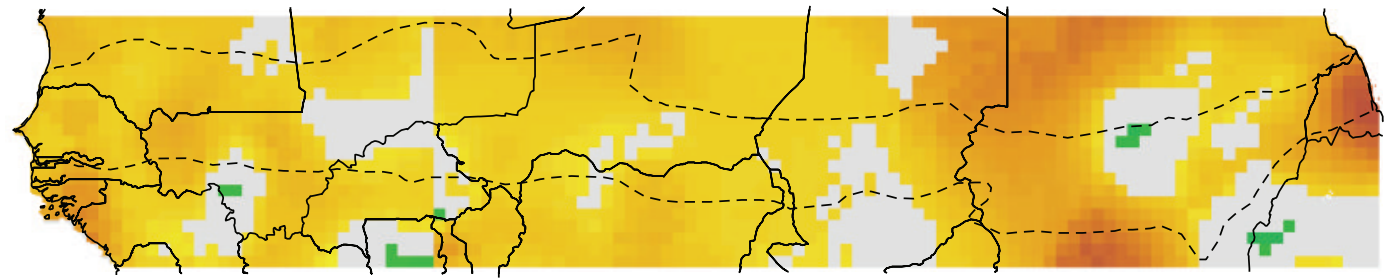

(c)

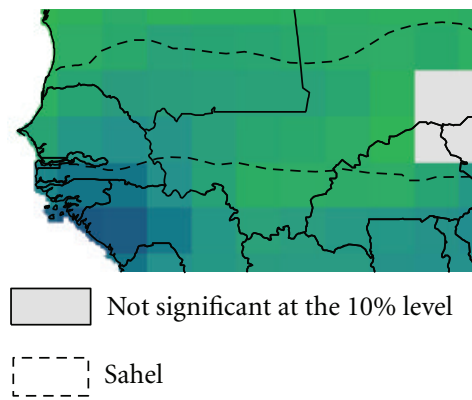

(a) NDVI slope (NDVI units/year) 0.01 $-0.01$ (b) Rainfall slope (mm/year)

30

$-30$
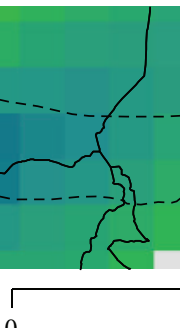

0

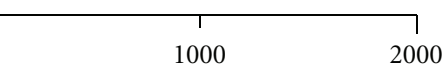

(Kilometers)

(c) Temperature slope

(d) Solar radiation

(degrees celcius/year)

(w/ $/ \mathrm{m}^{2} /$ year $)$

0.15

1.5

$-0.15$

$-1.5$

(d)

FIgure 3: Per-pixel linear trend analysis Sahel 1982-2007 of (a) GIMMS NDVI anomalies, (b) CMAP rainfall anomalies, (c) NCEP GHCN/CAMS gridded air temperature, and (d) NCEP-DOE gridded surface downward solar radiation flux anomalies. Anomalies are with respect to the 1982-2007 average.

none of the negative trends within the boundary of the Sahel are significant at the $10 \%$ confidence level. Furthermore, there is a difference in rainfall trends between the western and eastern part of the Sahel, with trends being consistently more significant in the western part as compared to the eastern Sahel. The overall trends in annual rainfall are similar to those of NDVI, with observable increases during the first half of the period under investigation (1982-2007) and no obvious tendency towards the end. This corresponds to the findings of Fensholt and Rasmussen (2011) [17], performing linear trend analysis on the GPCP data with a $2.5 * 2.5$ degree spatial resolution. The authors similarly discovered positive trends for the entire Sahelo-Sudanian zone, with approximately half the pixels being significant at the $10 \%$ level. Additionally, this corresponds to the findings of Nicholson (1993) [49] and Kandji et al. (2006) [7], who identified 1988 as the year ending the downward trend in annual rainfall in the Sahel, and a general recovery of the 


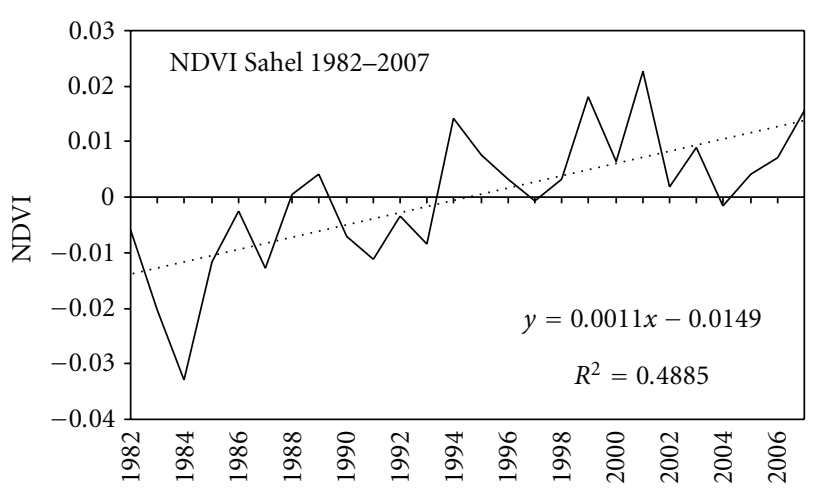

(a)

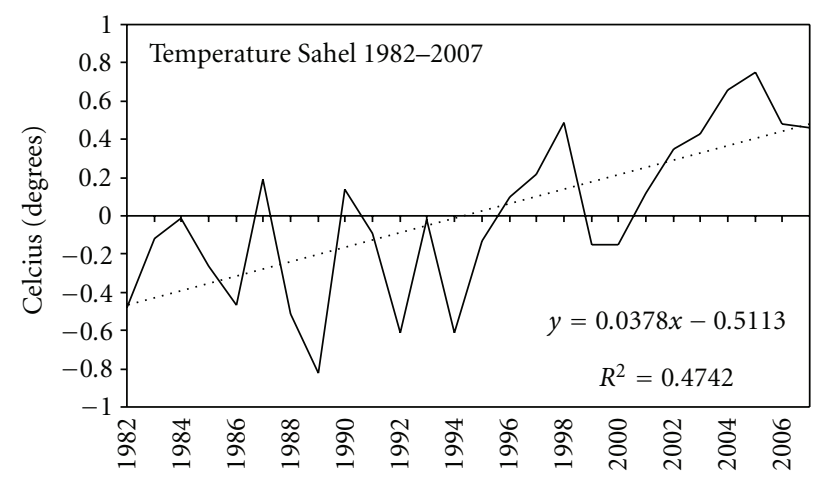

(c)

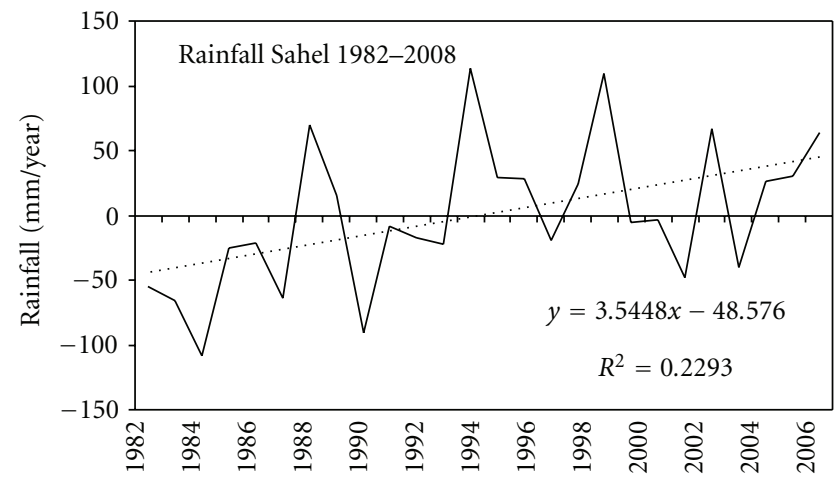

(b)

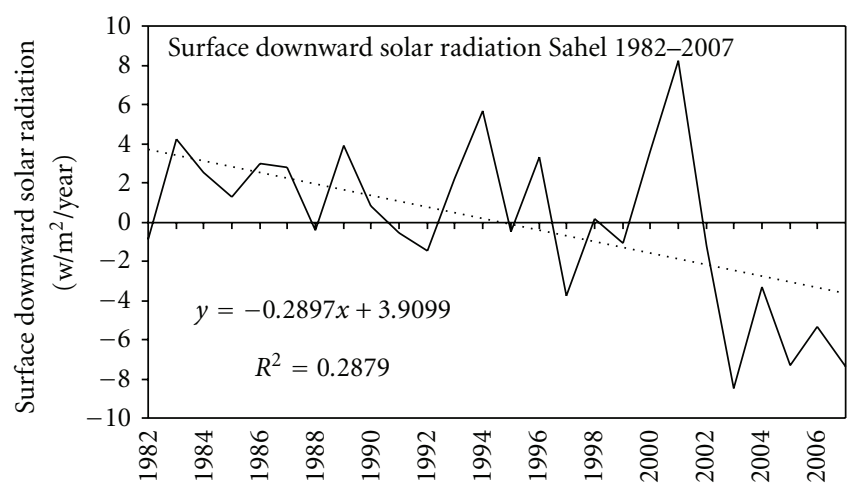

(d)

FIGURe 4: Linear trend analysis Sahel 1982-2007 of (a) GIMMS NDVI anomalies, (b) CMAP rainfall anomalies, (c) NCEP GHCN/CAMS gridded air temperature, and (d) NCEP-DOE gridded surface downward solar radiation flux anomalies. Anomalies are with respect to the 1982-2007 average.

rains from 1985-onwards. This pattern is not unexpected due to the timing of the start year of the trend analysis. However, in the context of the long-term climatic history in the Sahel, the past 30 years of moisture increase still leaves annual amounts of rainfall well below the wetter conditions that prevailed in the region from 1930 to 1965 [45]. As a consequence, recent increases may only be an indication of partial recovery following the severe droughts in the early 1980's.

Air temperature increases are consistent throughout a major part of the Sahelian area (Figure 3(c)), with only a few sites having experienced a downwards trend during the period 1982-2007. Only small areas are characterized by trends which are not significant at the $10 \%$ confidence level, and the result from the linear trend analysis reveals average slope values of $0.035^{\circ} \mathrm{C}$. This amounts to a $1{ }^{\circ} \mathrm{C}$ increase in average temperatures during the past 30 years. It is noticeable that temperature increases of $>3^{\circ} \mathrm{C}$ (slopes $>0.10$ ) are found in the most eastern part of the Sahel. The trends in air temperature exhibit a different temporal pattern, as compared to NDVI and rainfall with increases being confined to the later part of the investigated period (19952007). The increase in average air temperature corresponds to the expected and observed global pattern of temperature change, which is conditioned by increased amounts of atmospheric greenhouse gases [50]. For comparison, global mean surface temperatures have raised by $0.74^{\circ} \mathrm{C} \pm 0.18^{\circ} \mathrm{C}$ over the last 100 years (1906-2005) [51] with global warming rates increasing towards the end of the period. The cause of the apparent $3-4^{\circ} \mathrm{C}$ increase in temperature for the most eastern parts of the Sahel during 1982-2007 is difficult to identify and requires further investigation. The trend of surface downward solar radiation flux (Figure 3(d)) is negative for the majority of the Sahel except from the easternmost part (Sudan) characterized by a significant $(10 \%$ level) positive trend. The slope values are however relatively low with most pixels displaying changes within $\pm 10 \mathrm{w} / \mathrm{m}^{2}$ during 1982-2007 with maximum trends of approximately $\pm 30 \mathrm{w} / \mathrm{m}^{2}$.

The increase in NDVI is larger in the beginning of the series (1982-1994) and more moderate towards the end (Figure 4(a)). Conversely, a slight decrease in the average NDVI value may be observable towards the end of the series, from approximately 2001 and onwards. Additionally, the entire period shows relatively large interannual variability picking out clearly the severe Sahelian drought around 1984 and the very productive year of 2001.

Similar to NDVI, it is evident that the majority of the increase in annual rainfall occurred in the first half of the timeseries (1982-1994). Having recovered from the 1980's droughts, no apparent long-term trend can be observed and large interannual variations dominate the region in 
more recent years. Large interannual rainfall variations are persistent throughout the entire period. Rainfall anomalies (ranging from $105 \mathrm{~mm}$ in 1984 to $110 \mathrm{~mm}$ in 1994) result in trends significant at lower levels as compared to NDVI.

Interestingly, the majority of the air temperature increase did not occur until after the mid 90's as no observable trend is apparent before this point in time (Figure 4(c)). Similar to rainfall the air temperature trends exhibit large interannual variability. However, for air temperature the variability is most noticeable during the first part of the period (1982-1994) and more moderate towards the end (1995-2007). Air temperature anomalies range from $-0.8^{\circ} \mathrm{C}$ in 1990 to $0.7^{\circ} \mathrm{C}$ in 2005 . The overall negative trend of the surface downward solar radiation flux for the Sahel (Figure $4(\mathrm{~d})$ ) can be subdivided into a period of relatively constant values (1982-1995) and a period of decreasing values (1996-2007), however with larger interannual variability.

5.2. Seasonal Trend Analysis. Seasonal trend analysis was performed on monthly GIMMS NDVI data, and results are presented as seasonal curves (Figure 5(a), monthly median values over the first and last 7 years), the phase 1 index series (Figure 5(b), direction of change), and the amplitude 1 index series (Figure 5(c), magnitude of change). It can be seen that the majority of the observed increase in NDVI (Figure 3(a)) can be associated with the months covering growing season, that is, the difference between the black line and the dashed black line in Figure 5(a) during August-October. The largest difference in NDVI values is found in September, with increases reaching roughly $0.08 \mathrm{NDVI}$. This corresponds to a $50 \%$ increase as compared to the average increase in NDVI between season and off-season values for the beginning of the period (black line: 0.13 in June and 0.26 in September). From the amplitude 1 index series (Figure 5(b)) a clear positive trend is evident indicating this increase in the difference between annual high/low values (amplitude of the seasonal curve) per year during 1982-2007. From the phase 1 index series (Figure 5(c)) a minor shift in the annual peak, towards an earlier date, can be observed. The $y$-axis on the phase 1 index series shows phase angle degrees (range of 0-360), and 1 phase angle degree corresponds to a movement of the annual peak of $\approx 1$ day. For the Sahel the average slope of the phase 1 trend is 0.46 days/year indicating that the onset of the growing season in 2007 began approximately two weeks earlier as compared to 1982.

The most noticeable change in CMAP rainfall over the period 1982-2007 is a relatively large increase in annual rainfall which is primarily confined to July-August (Figure 5(d)). For August (annual peak), a remarkable increase in average rainfall of $40 \mathrm{~mm}$ (or about 50\%) can be identified. Only a minor increase is found for July whereas the remaining months of the rainy season are unchanged. The amplitude 1 index series (Figure 5(e)) show a clear positive trend illustrating this increase in amplitude of the seasonal curve per year during 1982-2007. The phase 1 index series (Figure 5(f)) reveal no major change in the timing of the annual peak with an average slope value of -0.05 days/year corresponding to a movement towards a later annual peak of $\approx 2$ days.

From the output of the STA of air temperature (Figure $5(\mathrm{~g})$ ) it is evident that the majority of the general increase in the average temperature of approximately $1^{\circ} \mathrm{C}$ (Figures 3(c) and 4(c)) is restricted to the period of OctoberJuly, that is, outside the months of the growing season. A positive trend in the amplitude 1 index series (Figure 5(h)) is clearly evident, indicating a decrease in the difference between annual high/low values (seasonal amplitude) during 1982-2007.

The reason for this decrease is the fact that temperatures have increased less during the summer months (warm months) as compared to the winter months (cold months) $($ see also Figure $5(\mathrm{~g})$ ). A minor positive trend $($ slope $=0.26$ ) in the phase 1 index series (Figure 5(i)) indicates a small shift in the timing of the annual temperature peak, of little more than a week, towards an earlier date. The STA analysis of surface downward solar radiation flux (Figures $5(\mathrm{j})-5(\mathrm{l})$ ) shows that the observed decreasing trend in solar radiation flux (Figures 3(d) and 4(d)) is primarily caused by decreasing fluxes during the growing season (June-October) whereas the dry season flux has been relatively stable. This also increases the amplitude of the surface downward solar radiation flux (Figure 5(k)); however the units are small $\left(<5 \mathrm{w} / \mathrm{m}^{2}\right)$ during 1982-2007. No changes in the phase of the surface downward solar radiation flux can be observed (Figure 5(1)).

The NDVI amplitude 1 image (Figure 6(a)) displays that approximately $50 \%$ of the area is characterized by significant trends ( $10 \%$ level), with the majority of these being located in the southern parts of the Sahel. This is in agreement with the results from the linear trend analysis where it was shown that NDVI values increased more in the southern than the northern areas (Figure 3(a)).

From the CMAP amplitude 1 image (Figure 6(b)) the positive trends indicate an increase in the difference between annual high/low values during 1982-2007. Approximately $60 \%$ of the Sahel features significant amplitude 1 trends at the $10 \%$ level, with the majority being located in the western and central areas. This indicates that the central and western Sahel experienced a significant increase in annual peak rainfall over the period 1982-2007.

Nearly $60 \%$ of the Sahel exhibits significant negative air temperature amplitude 1 trends with a minor tendency towards the northern parts having more pixels of significant values as compared to the southern Sahel. Significant positive amplitude 1 trends in surface downward solar radiation flux were found in the central and eastern Sahel (Figure 6(d)) expressing that the difference between the dry and wet season incoming solar radiation flux has increased.

As shown in Figure 7(a) approximately $25 \%$ of the Sahelian pixels are characterized by significant NDVI phase 1 trends (10\% level), with the majority being located in the northern Sahel. To identify changes in the length of the growing season (LGS), the onset/end was defined as the period in time where $40 \%$ of the fraction from minimum to maximum NDVI is passed. This percentage threshold was set relatively high since values below $20-25 \%$ increase the error 


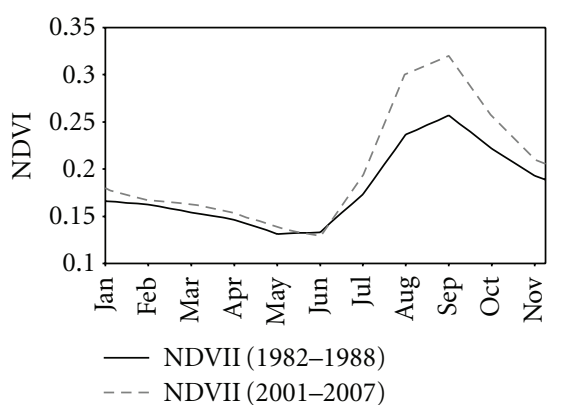

(a)

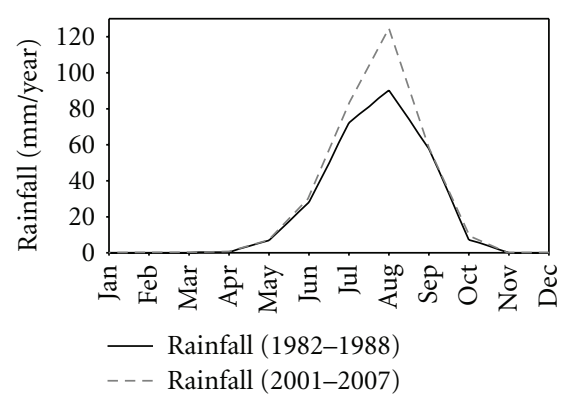

(d)

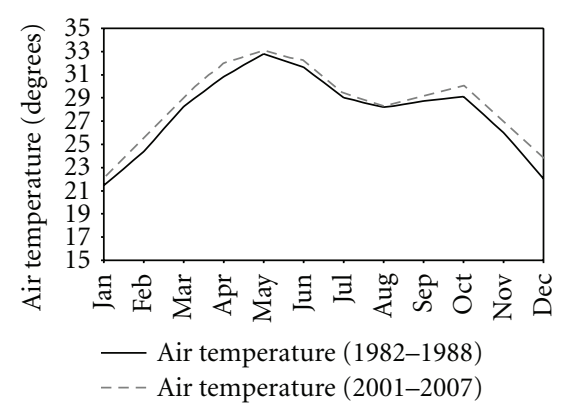

(g)

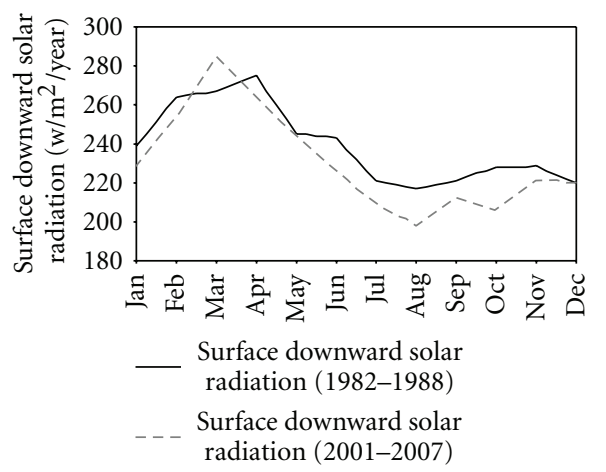

(j)

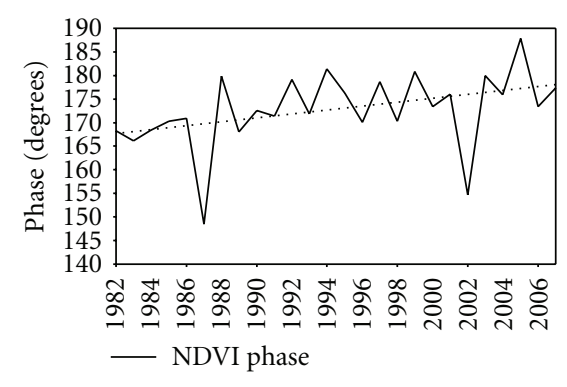

(b)

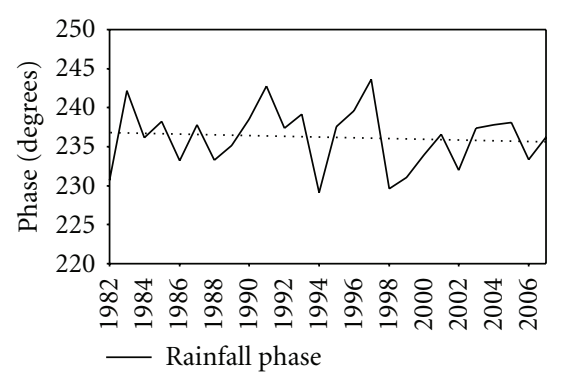

(e)

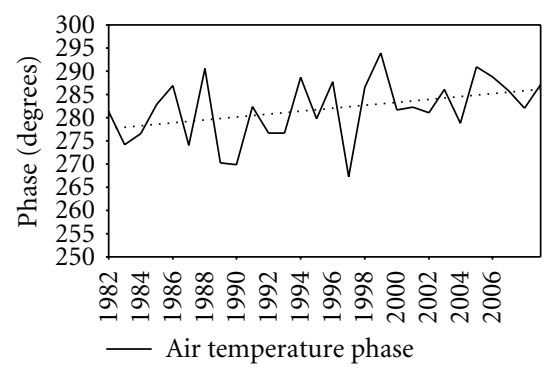

(h)

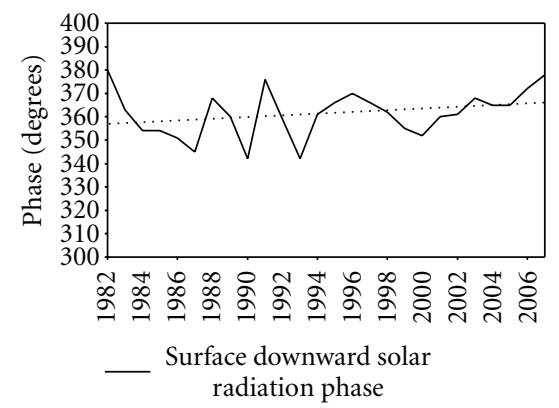

(k)

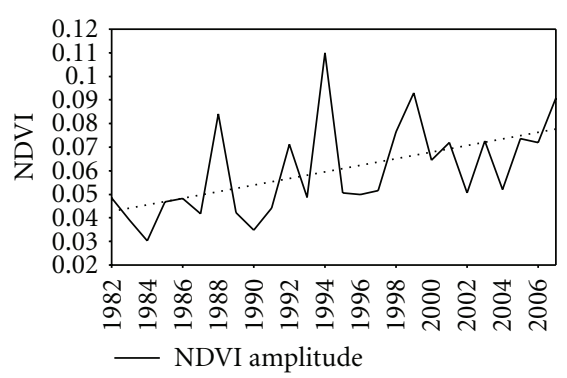

(c)

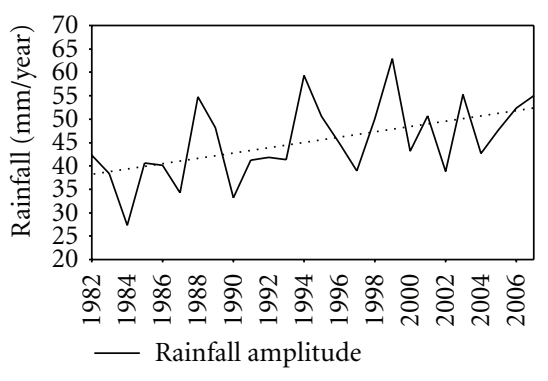

(f)

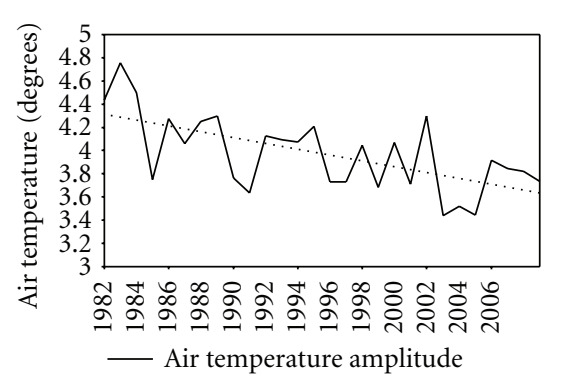

(i)

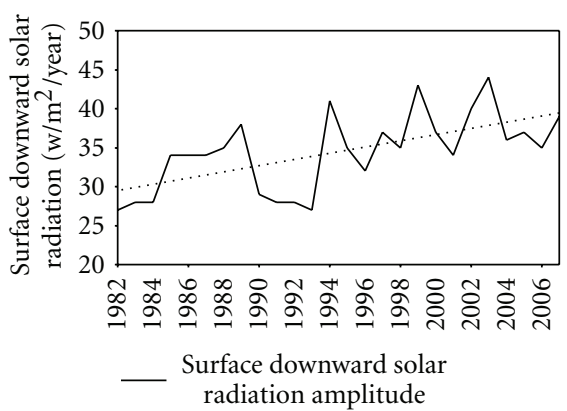

(l)

Figure 5: (a) Observed seasonal NDVI curves, Sahel 1982-2007 (black line: first 7 years, dashed black line: last 7 years). (b) NDVI amplitude 1 index series, Sahel 1982-2007. (c) NDVI phase 1 index series, Sahel 1982-2007. (d) Observed seasonal rainfall curves. (e) Rainfall amplitude 1 index series. (f) Rainfall phase 1 index series. (g) Observed seasonal air temperature curves. (h) Air temperature amplitude 1 index series. (i) Air temperature phase 1 index series. (j) Observed seasonal surface downward solar radiation flux. (k) Surface downward solar radiation flux amplitude 1 index series. (1) Surface downward solar radiation flux phase 1 index series. 


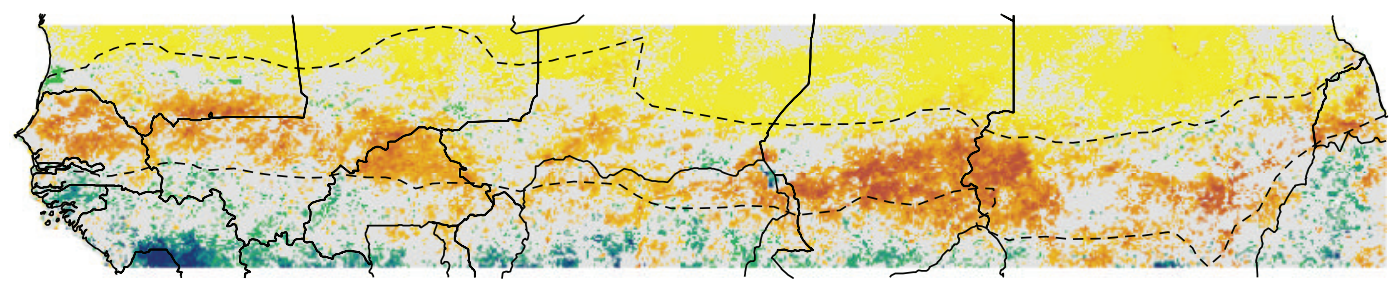

(a)

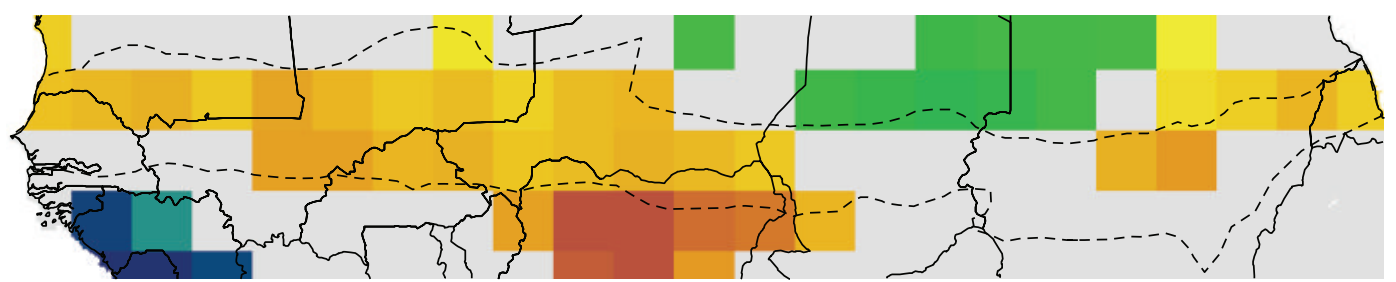

(b)

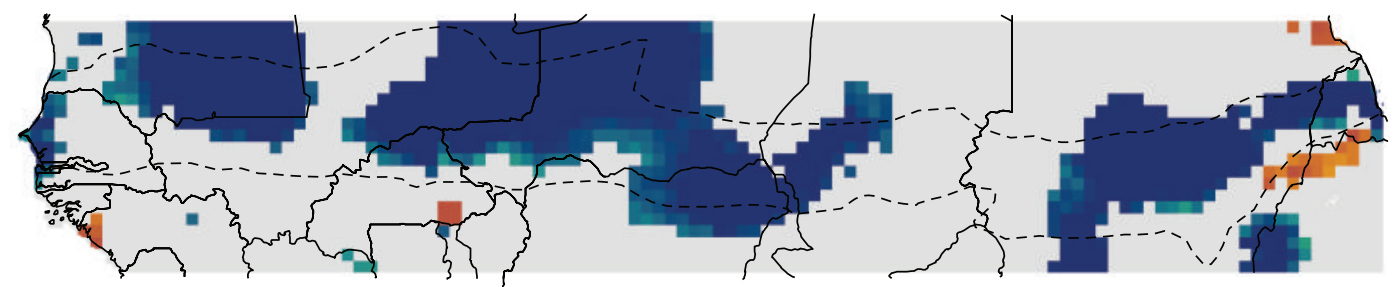

(c)

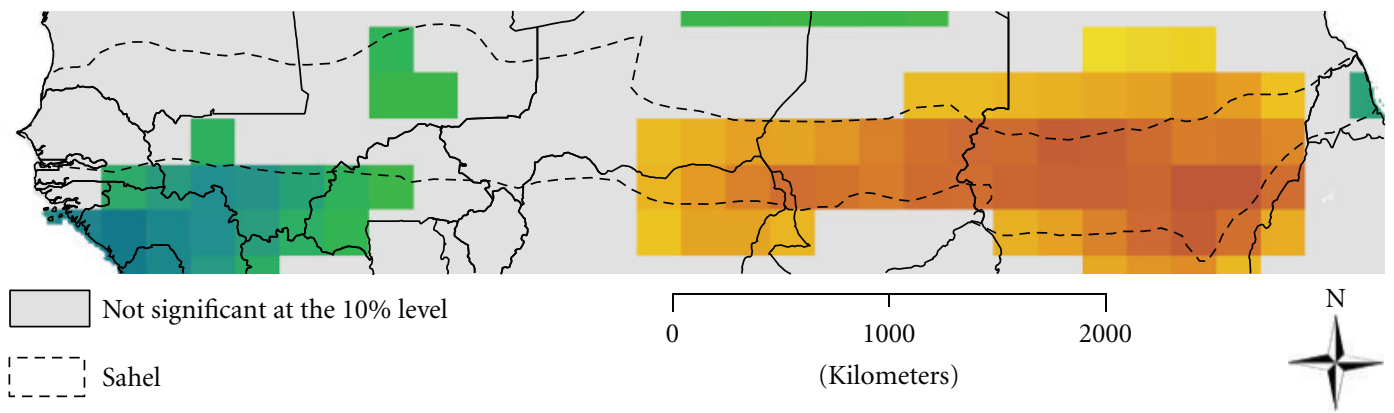

(a) NDVI slope (NDVI units/year)

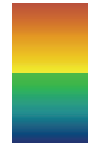

0.005

$-0.005$ (b) Rainfall slope (mm/year)
2

$-2$ (c) Temperature slope (degrees celcius/year) 0.03 $-0.03$

(d) (d) Solar radiation $\left(\mathrm{w} / \mathrm{m}^{2} /\right.$ year $)$

1.5

$-1.5$

FIgURE 6: STA amplitude 1 images, Sahel 1982-2007 (only slopes significant at the 10\% level). Changes in the amplitude of the seasonal (a) NDVI curve, (b) rainfall, (c) air temperature, and (d) surface downward solar radiation flux.

due to dry season noise [52]. The results show that the LGS have increased by approximately 4 weeks, initiating 2 weeks earlier and finishing 2 weeks later, in 2007 as compared to 1982.

From Figure 7(b) it can be seen that none of the pixels, within the Sahelian zone, was mapped with significant phase 1 rainfall trends. This indicates that no movement of the annual rainfall peak has occurred during 1982-2007. An analysis of the length of the rainy season was performed using a fraction of $20 \%$ of maximum rainfall (seasonal sum) indicating the beginning and end of the rainy season. $20 \%$ was selected, as compared to $40 \%$ for vegetation growth, due to the importance of the timing of the early rains in initiating the growing season [20,22]. The result of the analysis showed no prolonging or reduction in the length of the rainy season during 1982-2007. In general the seasonal trend analysis of the CMAP rainfall data does not show any remarkable spatial variability or change in either the length or position of the rainy season during the period of investigation. The lack of spatial variation in the outcome of the STA is partially 


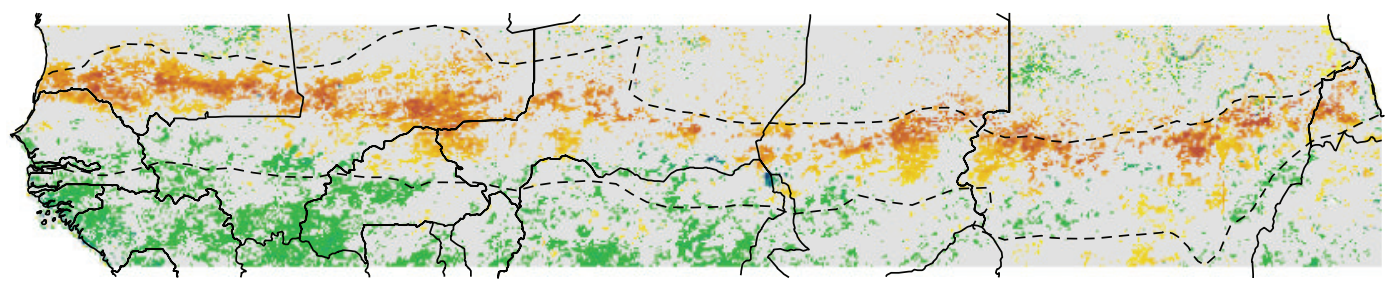

(a)

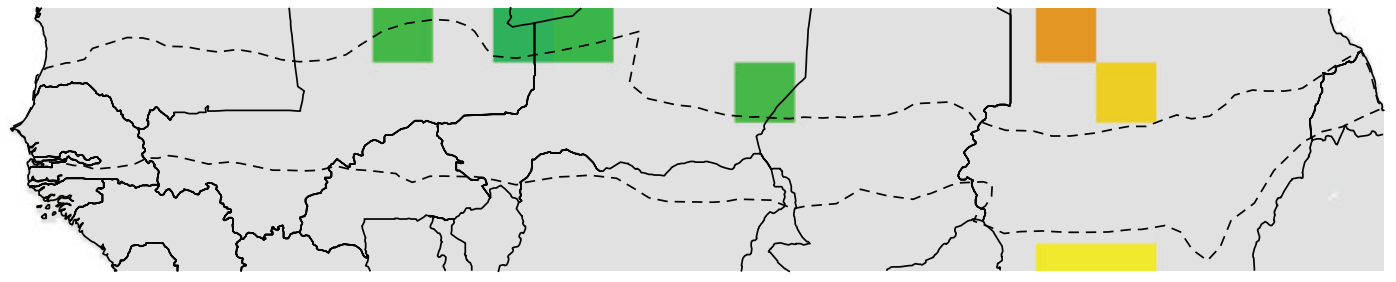

(b)

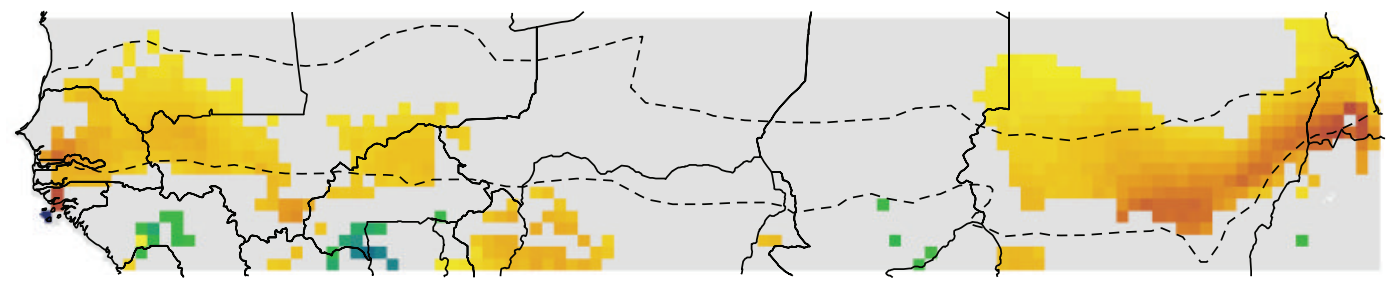

(c)

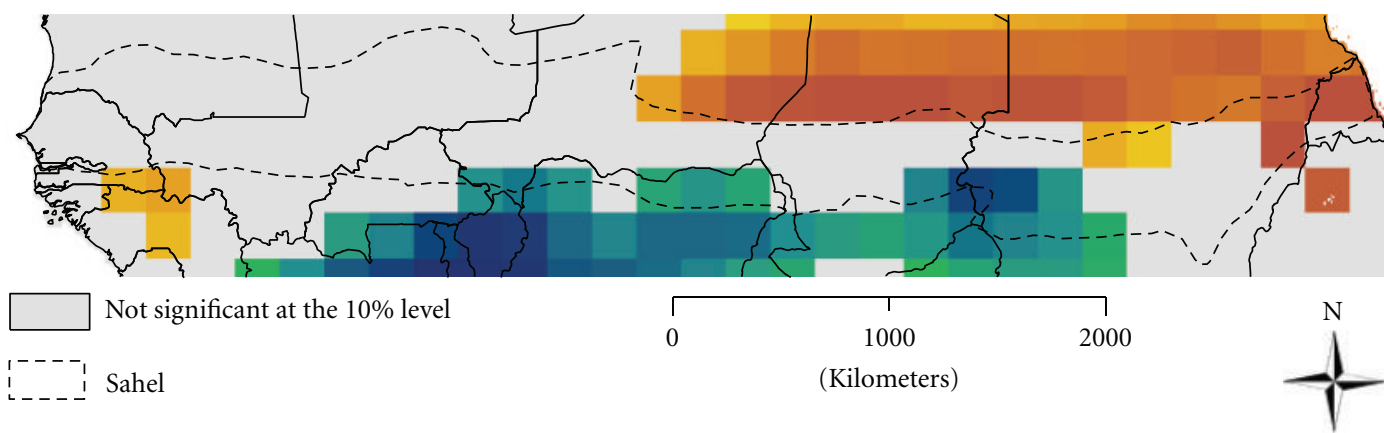

$\begin{array}{lllc}\begin{array}{l}\text { (a) NDVI slope } \\ \text { (degrees/year) }\end{array} & \begin{array}{l}\text { (b) Rainfall slope } \\ \text { (degrees/year) }\end{array} & \begin{array}{l}\text { (c) Temperature slope } \\ \text { (degrees/year) }\end{array} & \begin{array}{l}\text { (d) Solar radiation } \\ \text { (degrees/year) }\end{array} \\ 5 & 5 & 2 & 1.5 \\ -5 & -5 & -2 & -1.5\end{array}$

(d)

FIgURE 7: STA phase 1 images, Sahel 1982-2007 (only slopes significant at the 10\% level). Changes in the phase of the seasonal (a) NDVI curve, (b) rainfall, (c) air temperature, and (d) surface downward solar radiation flux.

conditioned by the coarse spatial resolution of the CMAP rainfall data and should be interpreted with this in mind.

Approximately $35 \%$ of the Sahelian area was identified as having significant $(10 \%$ level $)$ air temperature phase 1 trend (Figure $7(\mathrm{c})$ ) with pixels of significant trends primarily being located in the most eastern and western parts of the Sahel. Similar to rainfall almost no pixels were found with significant movement of the seasonal pattern of surface downward solar radiation flux for the Sahel during 19822007 (Figure 7(d)).
5.3. Climatic Drivers for NDVI Trends. The linear least squares regression analysis of annual NDVI against annual CMAP rainfall for 1982-2007 (Figure 8(a)) revealed a belt of pixels with significant positive $r$-values for the Sahelian zone, with $65 \%$ of the pixels being significant at the $10 \%$ confidence level (average $r=0.32$ ). There may be some evidence of a stronger relation during the first half of period (1982-1994) (Figures 4(a) and 4(b)), following the droughts of the early 80 's, as compared to the more recent years. In comparison Martiny et al. (2006) [53] identified 


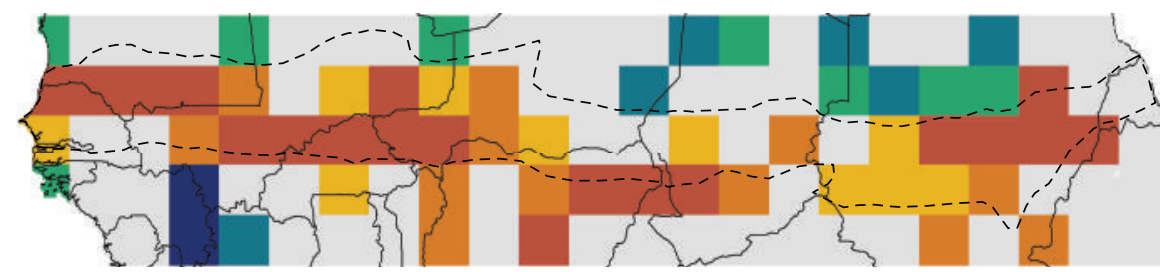

(a)

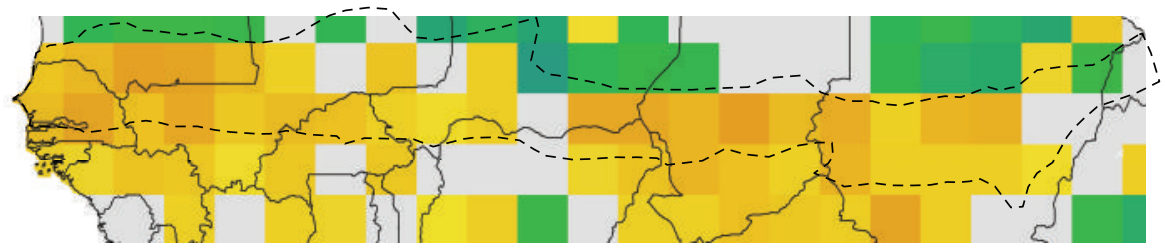

(b)

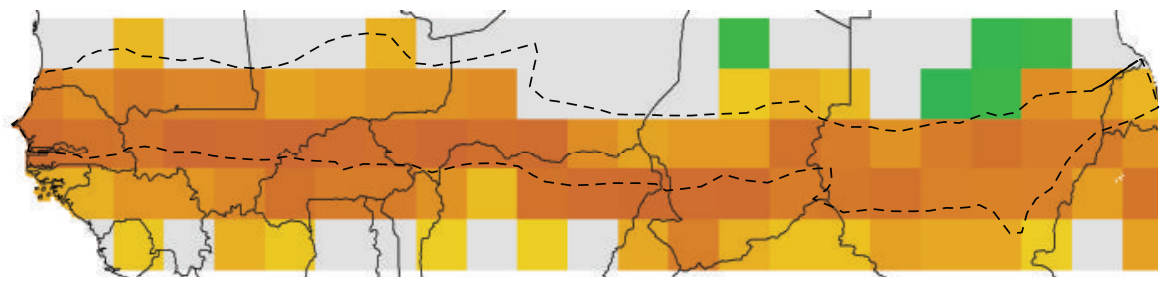

(c)

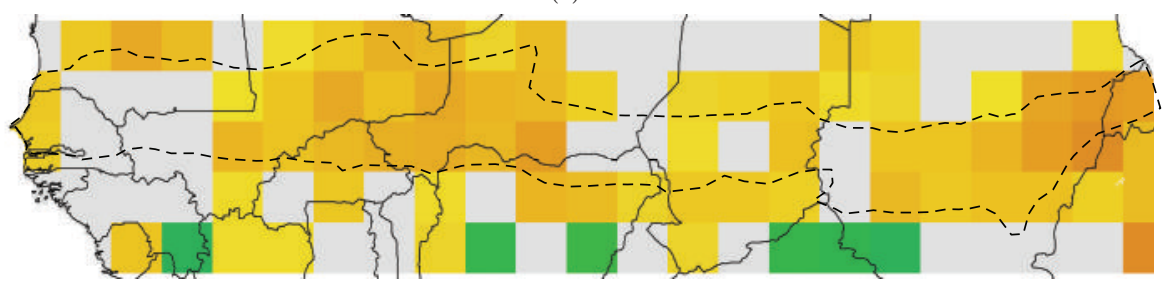

(d)

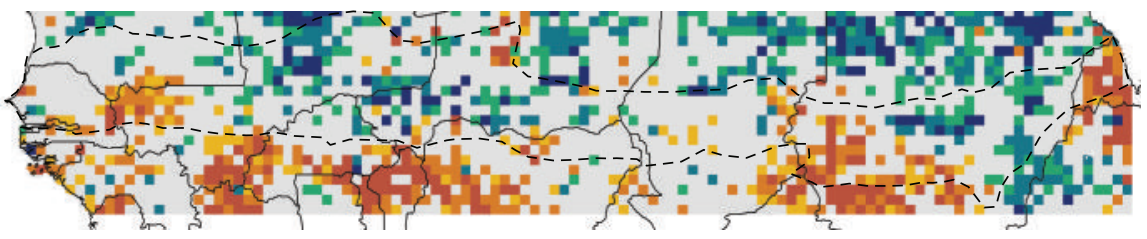

(e)

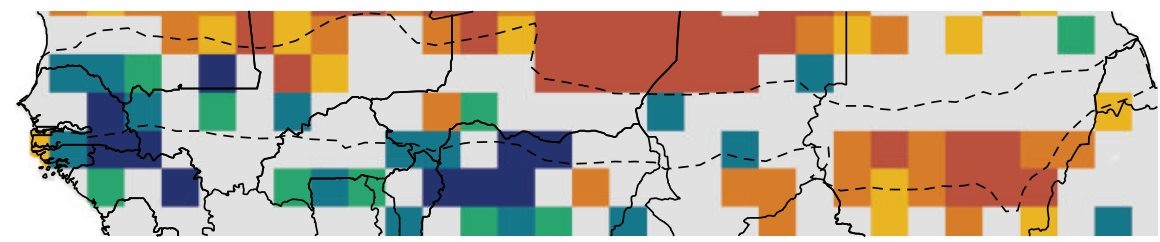

$r$-value (annual data $(\mathrm{a}, \mathrm{e}, \mathrm{f})) \quad r$-value (monthly data $(\mathrm{b}, \mathrm{c}, \mathrm{d})$ )
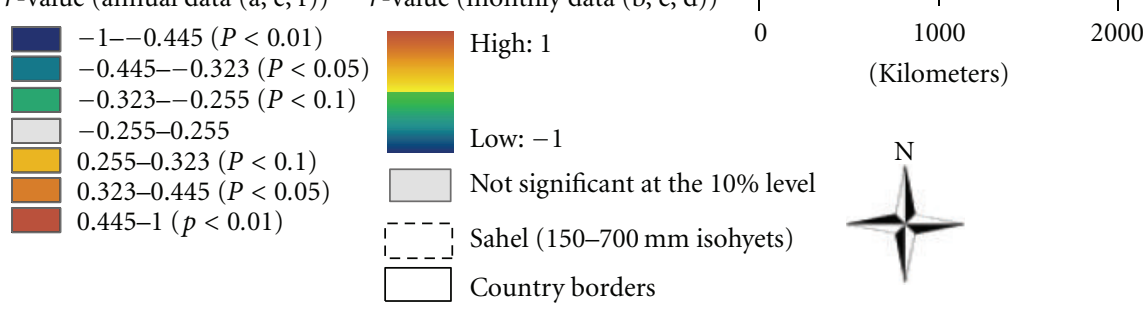

(Kilometers)

(f)

FIgURe 8: Annual correlations 1982-2007. (a) Annual NDVI/CMAP rainfall correlation. (b) Monthly GIMMS NDVI/CMAP rainfall correlation (June-October) no time lag. (c) Monthly GIMMS NDVI/CMAP rainfall correlation (June-October) one-month NDVI time lag. (d) Monthly GIMMS NDVI/CMAP rainfall correlation (June-October) two-month NDVI time lag. (e) Annual NDVI/air temperature correlation. (f) Annual NDVI/surface downward solar radiation flux correlation. 
an average $r$-value of $0.65(P<0.001)$ for the annual $\mathrm{NDVI} /$ rainfall (interpolated gauge data $0.5^{\circ}$ resolution) relationship, covering the semiarid regions of Africa, during the period of 1981-1995. Fensholt and Rasmussen (2011) [17] report that on average $20 \%(r=0.45)$ of the NDVI variance in the growing season can be attributed to the variance in annual rainfall in the Sahel.

The results of the linear regression analysis of monthly GIMMS NDVI against monthly CMAP rainfall (Figures $8(\mathrm{~b})-8(\mathrm{~d}))$ show correlations for the Sahelian zone with $65 \%, 90 \%$, and $80 \%$ of the pixels being significant $(10 \%$ level) at delayed vegetation responses of zero, one, and two months, respectively. Average $r$-values for the Sahel similarly differ with varying NDVI lagging time and amount to 0.16, 0.53 , and 0.26 for zero-, one-, and two- month delayed response time, respectively. From this it may be concluded that the optimum response time of vegetation to rainfall is approximately one month. This is similar to the findings of Eklundh (1998) [52], who analyzed the relationship between NDVI and rainfall for East Africa during the period 19821990. Martiny et al. (2006) [53] also identified a lag in vegetation response to rainfall of 1 month for West-Africa and the Sahel. The explanatory strength of CMAP rainfall tends to increase with decreasing latitude within Sahel for both annual and monthly relations (Figure 8(c)). As the most northern Sahel is covered with very sparse vegetation covers, the NDVI signal may be affected by soil background effects in these areas, and the weaker relation at higher latitudes may be a consequence hereof.

It is likely that several other contributory factors are influencing the relation between NDVI and rainfall. The data quality of the dataset applied here might add a considerable amount of noise to the analysis, and the very large pixel size of the CMAP data will evidently also eliminate the detection of variability at finer spatial scales. Additionally other explanations such as natural phenomena related to the response of vegetation to rainfall at different phenological stages and also various anthropogenic impacts, including land use and land cover changes, changes in grazing pressures, agricultural intensification, and altered migration patterns [44] can be included. The lagged effect of high/low rainfall values in one year on the amount of NDVI in consecutive years may similarly influence the observed relationship between NDVI and rainfall [54]. A different type of influence is the fertilizing effect of increased atmospheric concentrations of $\mathrm{CO}_{2}$ [55], which may similarly reduce the explanatory strength of rainfall.

The linear correlation analysis between annual NDVI and annual temperature does not reveal any strong relation. $R$ values average -0.03 for the entire Sahel with only $15 \%$ and $21 \%$ of the pixels displaying significant positive and negative correlations, respectively (Figure $8(\mathrm{e})$ ). This was expected since the observed increase in the Sahelian air temperature was found to be confined to the months covering the dry season (Figure 5(g)). The correlation between NDVI and surface downward solar radiation flux (Figure 8(f)) revealed a mixed pattern of pixels being both statistically significant (both positive and negative correlations) and insignificant indicating no consistent explanatory power of solar radiation flux on NDVI variance. The only area with a consistent significant positive covariance between solar radiation flux and NDVI is the southern part of Sudan.

\section{Conclusions}

Spatiotemporal trend analyses of EO-based and modelled/gridded biophysical variables show that the Sahel features persistent variability and change in vegetation dynamics (NDVI) and potential climatic constraints to plant growth (rainfall, air temperature, and surface downward solar radiation flux) over the past three decades. The magnitude, direction, and association of these trends have been assessed. An increase in observed NDVI over the full period (19822007), primarily associated with a strong greening trend until 1994, was found in accordance with previous work. This study improves the existing knowledge by studying both inter- and intra-annual changes in greenness and potential climatic constraints to plant growth in the Sahel. The greening was confined to the months covering the growing season (Jul-Oct), reaching 50\% on average for September. And the length of the Sahelian growing season has increased by approximately 4 weeks ( 2 weeks earlier onset and 2 weeks later ending date). This corresponds well with rainfall TSLTA and STA revealing an increasing trend for the first part of the period (1982-1994) and that the increases occurred during August (the months of peak rainfall). However, no significant change in the length of the rainy season was observed over the period 1982-2007. This indicates that the last three decades of the Sahelian environment can be characterized by different phases covering the eightiesmid-nineties and mid-nineties-present, respectively. The observed increase in air temperature was confined to the last part of the period (1995-2007).

The degree NDVI variance being explained by rainfall was found to be moderate at the Sahel scale using growing season monthly values of NDVI lagging rainfall by one month $(r=0.53)$. The moderate explanatory strength of rainfall (as well as air temperature/solar radiation flux) points towards the importance of other contributory factors including data quality, plant phenology, and anthropogenic influence in determining vegetation dynamics. In view of the fact that semi-arid rangeland dynamics are highly responsive to climatic variability and change it is important to continue improving the possibilities for accurate monitoring of the relation between important biophysical variables, anthropogenic impacts, and the condition of the natural vegetation cover. This is especially important in relation to the establishment of appropriate mitigation and adaptation measures towards future climate change.

\section{References}

[1] P. Smithson, K. Addison, and K. Atkinson, Fundamentals of the Physical Environment, Routledge Taylor \& Francis Group, London, UK, 4th edition, 2008.

[2] K. M. Leisinger and K. Schmitt, Survival in the Sahel-An Ecological and Developmental Challenge, The International Service for Agricultural Research (ISNAR), 1995. 
[3] M. Boko, I. Niang, A. Nyong et al., "Africa," in Climate Change 2007: Impacts, Adaptation and Vulnerability. Contribution of Working Group II to the Fourth Assessment Report of the Intergovernmental Panel on Climate Change, M. L. Parry, O. F. Canziani, J. P. Palutikof, P. J. van der Linden, and C. E. Hanson, Eds., pp. 433-467, Cambridge University Press, Cambridge, UK, 2007.

[4] N. Zeng, "Drought in the Sahel," Science, vol. 302, no. 5647, pp. 999-1000, 2003.

[5] M. Hulme, "Climatic perspectives on Sahelian desiccation: 1973-1998," Global Environmental Change, vol. 11, no. 1, pp. 19-29, 2001.

[6] S. E. Nicholson and J. P. Grist, "A conceptual model for understanding rainfall variability in the West African Sahel on interannual and interdecadal timescales," International Journal of Climatology, vol. 21, no. 14, pp. 1733-1757, 2001.

[7] S. T. Kandji, L. Verchot, and J. Mackensen, Climate Change and Climate Variability in the Sahel Region: Impacts and Adaptation Strategies in the Agricultural Sector, World Agroforesty Centre, UNEP, 2006.

[8] IPCC, "Intergovernmental panel on climate change," Fourth Assessment Report (AR4), Working Group II Report (WGI) Climate Change 2007: Working Group II: Impacts, adaptation and vulnerability, 2007.

[9] W. Steffen, A. Sanderson, P. D. Tyson et al., Global Change and the Earth System: A Planet Under Pressure, IGBP Book, 2004.

[10] C. B. Field, F. S. Chapin III, P. A. Matson, and H. A. Mooney, "Responses of terrestrial ecosystems to the changing atmosphere: a resource-based approach," Annual Review of Ecology and Systematics, vol. 23, no. 1, pp. 201-235, 1992.

[11] S. M. Herrmann, A. Anyamba, and C. J. Tucker, "Recent trends in vegetation dynamics in the African Sahel and their relationship to climate," Global Environmental Change, vol. 15, no. 4, pp. 394-404, 2005.

[12] T. Hickler, L. Eklundh, J. W. Seaquist et al., "Precipitation controls Sahel greening trend," Geophysical Research Letters, vol. 32, no. 21, Article ID L21415, pp. 1-4, 2005.

[13] Y. H. Kerr, J. Imbernon, G. Dedieu, O. Hautecoeur, J. P. Lagouarde, and B. Seguin, "NOAA-AVHRR and its uses for rainfall and evapotranspiration monitoring," International Journal of Remote Sensing, vol. 10, no. 4-5, pp. 847-854, 1989.

[14] A. R. Malo and S. E. Nicholson, "A study of rainfall and vegetation dynamics in the African Sahel using normalized difference vegetation index," Journal of Arid Environments, vol. 19, no. 1, pp. 1-24, 1990.

[15] S. D. Prince, E. B. de Colstoun, and L. L. Kravitz, "Evidence from rain-use efficiencies does not indicate extensive Sahelian desertification," Global Change Biology, vol. 4, no. 4, pp. 359374, 1998.

[16] R. R. Nemani, C. D. Keeling, H. Hashimoto et al., "Climatedriven increases in global terrestrial net primary production from 1982 to 1999," Science, vol. 300, no. 5625, pp. 1560-1563, 2003.

[17] R. Fensholt and K. Rasmussen, "Analysis of trends in the Sahelian "rain-use efficiency" using GIMMS NDVI, RFE and GPCP rainfall data," Remote Sensing of Environment, vol. 115, no. 2, pp. 438-451, 2011.

[18] S. E. Nicholson, "Sahel, West Africa," Encyclopedia of Environmental Biology, vol. 3, pp. 261-275, 1995.

[19] P. Mayaux, E. Bartholomé, M. Massart et al., A Land-Cover Map of Africa, Office for Official Publications of the European Communities, Luxembourg, 2003.

[20] P. Hiernaux, E. Mougin, L. Diarra et al., "Sahelian rangeland response to changes in rainfall over two decades in the
Gourma region, Mali," Journal of Hydrology, vol. 375, no. 12, pp. 114-127, 2009.

[21] T. Lebel and A. Ali, "Recent trends in the Central and Western Sahel rainfall regime (1990-2007)," Journal of Hydrology, vol. 375, no. 1-2, pp. 52-64, 2009.

[22] M. E. Brown, The Famine Early Warning Systems and Remote Sensing Data, Springer, 2008.

[23] C. J. Tucker, J. E. Pinzon, M. E. Brown et al., "An extended AVHRR 8-km NDVI dataset compatible with MODIS and SPOT vegetation NDVI data," International Journal of Remote Sensing, vol. 26, pp. 4485-4498, 2005.

[24] D. Ramier, N. Boulain, B. Cappelaere et al., "Towards an understanding of coupled physical and biological processes in the cultivated Sahel-1. Energy and water," Journal of Hydrology, vol. 375, no. 1-2, pp. 204-216, 2009.

[25] Y. Fan and H. van den Dool, "A global monthly land surface air temperature analysis for 1948-present," Journal of Geophysical Research D, vol. 113, no. 1, Article ID D01103, 2008.

[26] M. E. James and S. N. V. Kalluri, "The pathfinder AVHRR land data set: an improved coarse resolution data set for terrestrial monitoring," International Journal of Remote Sensing, vol. 15, no. 17, pp. 3347-3363, 1994.

[27] E. Vermote and Y. J. Kaufman, "Absolute calibration of AVHRR visible and near-infrared channels using ocean and cloud views," International Journal of Remote Sensing, vol. 16, no. 13, pp. 2317-2340, 1995.

[28] S. O. Los, "Estimation of the ratio of sensor degradation between NOAA AVHRR channels 1 and 2 from monthly NDVI composites," IEEE Transactions on Geoscience and Remote Sensing, vol. 36, no. 1, pp. 206-213, 1998.

[29] J. E. Pinzon, M.E. Brown, and C. J. Tucker, "HilbertHuang transform and its applications," in Interdisciplinary Mathematical Sciences, N. E. Huang, Ed., vol. 5, p. 12, World Scientific, London, UK, 2005.

[30] P. Xie and P. A. Arkin, "Global precipitation: a 17-year monthly analysis based on Gauge observations, satellite estimates, and numerical model outputs," Bulletin of the American Meteorological Society, vol. 78, no. 11, pp. 2539-2558, 1997.

[31] M. Kanamitsu, W. Ebisuzaki, J. Woollen et al., "NCEPDOE AMIP-II reanalysis (R-2)," Bulletin of the American Meteorological Society, vol. 83, no. 11, pp. 1631-1643, 2002.

[32] U. Helldén and C. Tottrup, "Regional desertification: a global synthesis," Global and Planetary Change, vol. 64, no. 3-4, pp. 169-176, 2008.

[33] R. Fensholt, K. Rasmussen, T. T. Nielsen, and C. Mbow, "Evaluation of earth observation based long term vegetation trends-intercomparing NDVI time series trend analysis consistency of Sahel from AVHRR GIMMS, Terra MODIS and SPOT VGT data," Remote Sensing of Environment, vol. 113, no. 9, pp. 1886-1898, 2009.

[34] H. Theil, "A rank-invariant method of linear and polynomial regression analysis. I, II and III," in Proceedings of the Koninklijke Nederlandse Akademie van Wetenschappen, vol. 53, pp. 386-392, 521-525, 1397-1412, 1950.

[35] P. K. Sen, "Estimates of the regression coefficient based on Kendall's tau," Journal of the American Statistical Association, vol. 63, pp. 1379-1389, 1968.

[36] D. C. Hoaglin, F. Mosteller, and J. W. Tukey, Understanding Robust and Exploratory Data Analysis, Wiley, New York, NY, USA, 2000.

[37] D. Alcaraz-Segura, E. Chuvieco, H. E. Epstein, E. S. Kasischke, and A. Trishchenko, "Debating the greening vs. browning of the North American boreal forest: differences between satellite 
datasets," Global Change Biology, vol. 16, no. 2, pp. 760-770, 2010.

[38] R. M. Hirsch and J. R. Slack, "A nonparametric trend test for seasonal data with serial dependence," Water Resources Research, vol. 20, no. 6, pp. 727-732, 1984.

[39] G. van Belle and J. P. Hughes, "Nonparametric tests for trend in water quality," Water Resources Research, vol. 20, no. 1, pp. 127-136, 1984.

[40] K. M. de Beurs and G. M. Henebry, "Land surface phenology and temperature variation in the International GeosphereBiosphere Program high-latitude transects," Global Change Biology, vol. 11, no. 5, pp. 779-790, 2005.

[41] S. Huber, R. Fensholt, and K. Rasmussen, "Water availability as the driver of vegetation dynamics in the African Sahel from 1982 to 2007," Global and Planetary Change, vol. 76, no. 3-4, pp. 186-195, 2011.

[42] J. Hill, M. Stellmes, T. Udelhoven, A. Röder, and S. Sommer, "Mediterranean desertification and land degradation. Mapping related land use change syndromes based on satellite observations," Global and Planetary Change, vol. 64, no. 3-4, pp. 146-157, 2008.

[43] J. R. Eastman, F. Sangermano, B. Ghimire et al., "Seasonal trend analysis of image time series," International Journal of Remote Sensing, vol. 30, no. 10, pp. 2721-2726, 2009.

[44] L. Olsson, L. Eklundh, and J. Ardö, "A recent greening of the Sahel-trends, patterns and potential causes," Journal of Arid Environments, vol. 63, no. 3, pp. 556-566, 2005.

[45] A. Anyamba and C. J. Tucker, "Analysis of Sahelian vegetation dynamics using NOAA-AVHRR NDVI data from 1981-2003," Journal of Arid Environments, vol. 63, no. 3, pp. 596-614, 2005.

[46] L. Eklundh and L. Olsson, "Vegetation index trends for the African Sahel 1982-1999," Geophysical Research Letters, vol. 30, no. 8, p. 1430, 2003.

[47] B. W. Heumann, J. W. Seaquist, L. Eklundh, and P. Jönsson, "AVHRR derived phenological change in the Sahel and Soudan, Africa, 1982-2005," Remote Sensing of Environment, vol. 108, no. 4, pp. 385-392, 2007.

[48] A. R. Huete, "A soil-adjusted vegetation index (SAVI)," Remote Sensing of Environment, vol. 25, no. 3, pp. 295-309, 1988.

[49] S. E. Nicholson, "An overview of African rainfall fluctuations of the last decade," Journal of Climate, vol. 6, no. 7, pp. 14631466, 1993.

[50] S. Solomon, D. Qin, M. Manning et al., "Technical summary," in Climate Change 2007: The Physical Science Basis. Contribution of Working Group I to the Fourth Assessment Report of the Intergovernmental Panel on Climate Change, S. Solomon, D. Qin, M. Manning et al., Eds., Cambridge University Press, Cambridge, UK, 2007.

[51] K. E. Trenberth, P. D. Jones, P. Ambenje et al., "Observations: surface and atmospheric climate change," in Climate Change 2007: The Physical Science Basis. Contribution of Working Group I to the Fourth Assessment Report of the Intergovernmental Panel on Climate Change, S. Solomon, D. Qin, M. Manning et al., Eds., Cambridge University Press, Cambridge, UK, 2007.

[52] L. Eklundh, "Estimating relations between AVHRR NDVI and rainfall in East Africa at 10-day and monthly time scales," International Journal of Remote Sensing, vol. 19, no. 3, pp. 563$568,1998$.

[53] N. Martiny, P. Camberlin, Y. Richard, and N. Philippon, "Compared regimes of NDVI and rainfall in semi-arid regions of Africa," International Journal of Remote Sensing, vol. 27, no. 23, pp. 5201-5223, 2006.
[54] S. D. Prince, K. J. Wessels, C. J. Tucker, and S. E. Nicholson, "Desertification in the Sahel: a reinterpretation of a reinterpretation," Global Change Biology, vol. 13, no. 7, pp. 1308-1313, 2007.

[55] K. Sherwood and C. Idso, "The greening of the sahel," CO2 Science, vol. 9, no. 2, 2006, Editorial comments. 

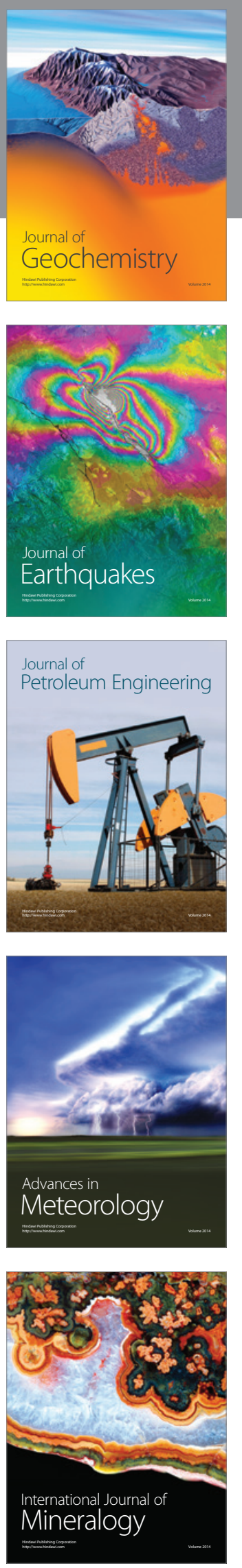
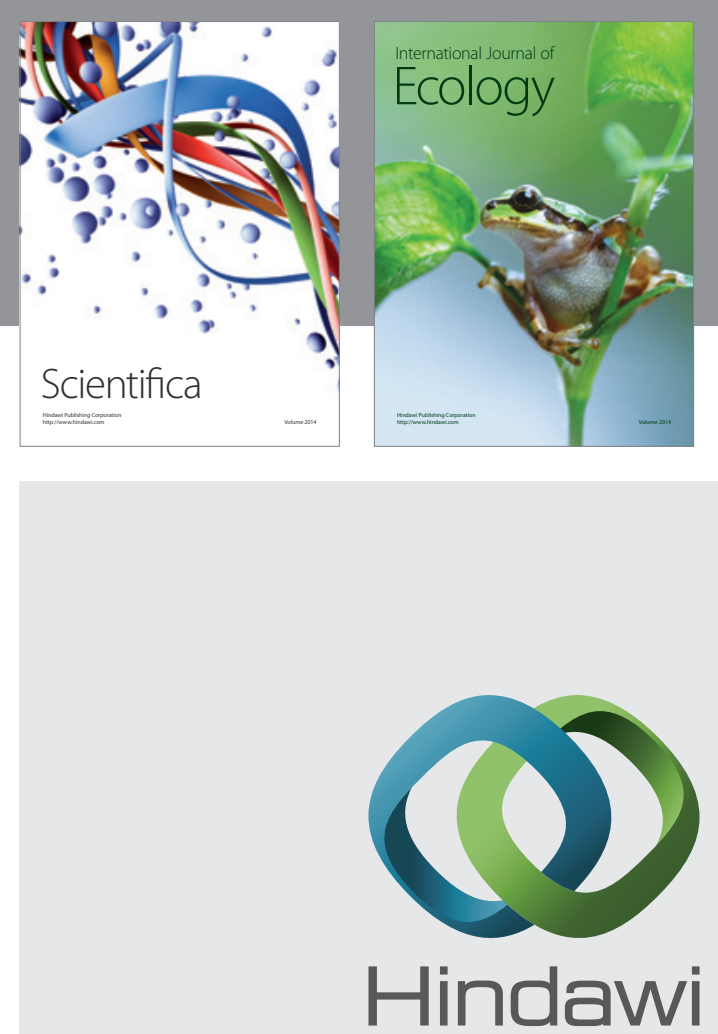

Submit your manuscripts at http://www.hindawi.com
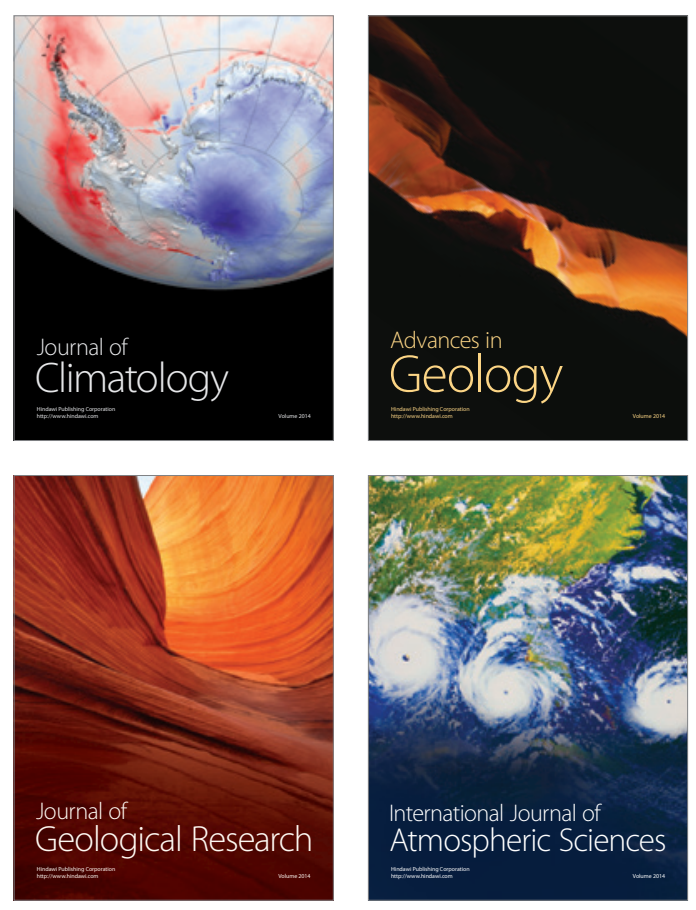
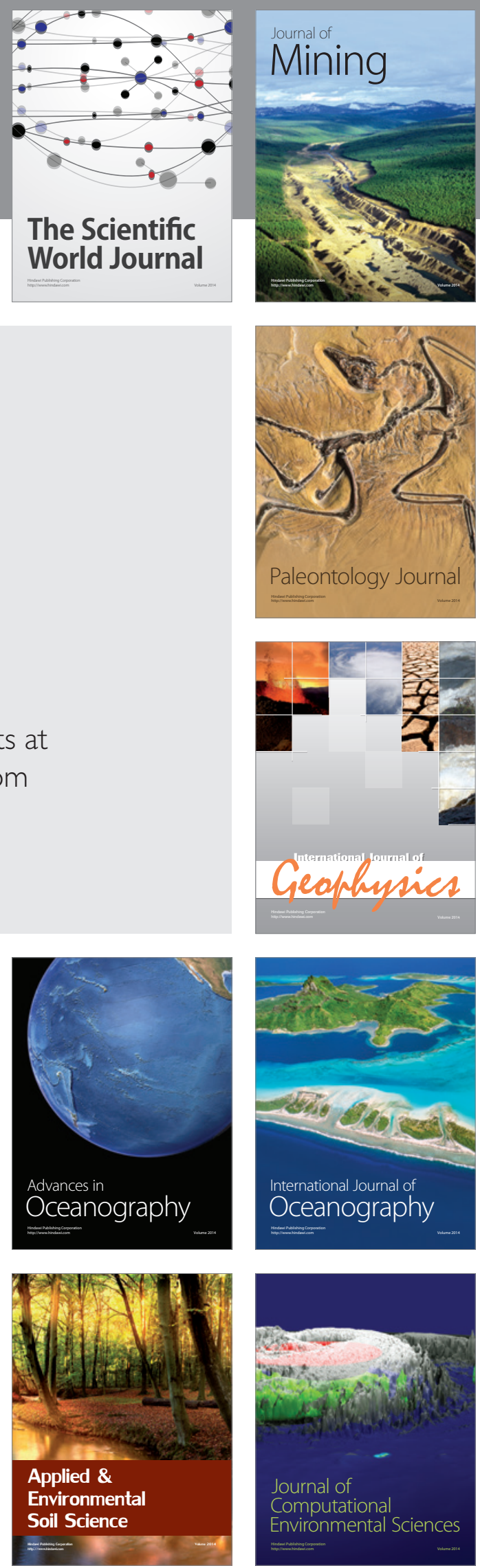